\title{
Novel Hybrid Ligands for Passivating PbS Colloidal Quantum Dots to Enhance the Performance of Solar Cells
}

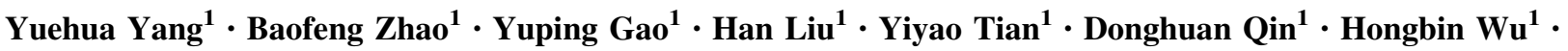 \\ Wenbo Huang ${ }^{1} \cdot$ Lintao Hou ${ }^{2}$
}

Received: 25 April 2015/Accepted: 30 June 2015/Published online: 20 June 2015

(C) The Author(s) 2015. This article is published with open access at Springerlink.com

\begin{abstract}
We developed novel hybrid ligands to passivate $\mathrm{PbS}$ colloidal quantum dots (CQDs), and two kinds of solar cells based on as-synthesized CQDs were fabricated to verify the passivation effects of the ligands. It was found that the ligands strongly affected the optical and electrical properties of CQDs, and the performances of solar cells were enhanced strongly. The optimized hybrid ligands, oleic amine/octyl-phosphine acid/ $\mathrm{CdCl}_{2}$ improved power conversion efficiency (PCE) to much higher of $3.72 \%$ for Schottky diode cell and $5.04 \%$ for $\mathrm{p}-\mathrm{n}$ junction cell. These results may be beneficial to design passivation strategy for low-cost and high-performance CQDs solar cells.
\end{abstract}

Keywords $\mathrm{PbS} \cdot$ Colloidal quantum dot $\cdot$ Solar cells $\cdot$ Ligands

\section{Introduction}

Colloidal quantum dots (CQDs) solar cells as potential next-generation solar energy-harvesting devices have received considerable attention in the past several years [14] owing to their low manufacturing cost (coated on substrates using drop-casting, spin-coating or ink-jet printing). Among all kinds of CQDs (such as CdTe [5-9], CdSe [10], $\mathrm{PbS}$ [11-14], PbSe [15-17], $\mathrm{CuInS}_{2}$ [18], etc.) solar cells, $\mathrm{PbS}$ CQDs solar cells have lots of distinctive merits. For example, PbS CQDs solar cells can be prepared in ambient condition under low temperatures below $200^{\circ} \mathrm{C}$, and the electronic bandgap of $\mathrm{PbS}$ CQDs can be easily tuned by changing size due to its large exciton Bohr radius ( $\sim 18 \mathrm{~nm}$ for $\mathrm{PbS}[19])$, which enables the fabrication of multi-junction solar cells from single material.

Donghuan Qin

qindh@scut.edu.cn

1 State Key Laboratory of Luminescent Materials \& Devices, Institute of Polymer Optoelectronic Materials \& Devices, South China University of Technology, Guangzhou 510640, People's Republic of China

2 Siyuan Laboratory, Department of Physics, Jinan University, Guangzhou 510632, People's Republic of China
PbS CQDs solar cells with negligible power conversion efficiency (PCE) were first reported in 2005 [20]. There are two key factors which affect the performance of PbS CQDs solar cells. The important one is protection technique of asprepared PbS CQDs. As the size decreases, the surface state of $\mathrm{PbS}$ will go up rapidly due to oxidation if there is no suitable ligand to protect. Devices based on no-protection $\mathrm{PbS}$ CQDs exclusively show large internal series resistance and low carrier mobility, resulting in low device performance. Meanwhile, since the long-chain carboxyl acid is usually attached to the surface of $\mathrm{PbS}$, it is difficult to gain satisfactory device performance unless the carboxyl ligands are well removed during device fabrication processes. With development of nanotechnology, many efforts had been made to improve the PCE of PbS CQDs solar cells, including packing and passivation of CQDs [21, 22], adoption of new exchanging ligands [23], and design of new device structure [24]. In order to improve surface passivation and therefore eliminate valence-band-associated trap states in CQDs thin film, Sargent et al. [25-27] first introduced a mixture of $\mathrm{CdCl}_{2}$ and tetradecyl phosphonic acid (TDPA) during synthesis process of PbS CQDs. They obtained solar cell device with $\sim 8.0 \%$ efficiency based on these hybrid passivated CQDs. On the other hand, new exchanging ligands such as mercaptopropionic acid (MPA) 
or di-thiol were introduced during device fabrication process to remove the long-chain carboxyl acid ligands on the surface of PbS CQDs. The thin film prepared by this method was compact and showed good carrier mobility.

In this paper, we developed a novel simple process of passivating $\mathrm{PbS}$ CQDs to improve the film quality and therefore to enhance the solar cells' performance. Different hybrid ligands were introduced during $\mathrm{PbS}$ nucleation and QDs growth processes. Two kinds of solar cells based on $\mathrm{PbS}$ CQDs were fabricated to verify the effects of ligands passivation.

\section{Experimental}

\subsection{Materials}

Oleic acid (OA, $90 \%$ ), lead oxide (PbO, 99.9\%), 1-octadecene (ODE), $\mathrm{CdCl}_{2}$, and oleic amine (OLA) were purchased from Alfa Aesar. Mercaptopropionic acid Hexamethyldisilathiane (TMS), octyl-phosphine acid (OPA), tetradecyl phosphonic acid (TDPA), and octodecyl-phosphine acid (ODPA) were purchased from Aladdin. All chemicals were used directly without any further purification.

\subsection{Synthesis of PbS CQDs}

PbS CQDs with different passivating ligands were defined as (A) without ligand, (B) $\mathrm{CdCl}_{2}+\mathrm{OLA}+\mathrm{OPA}$, (C) $\mathrm{CdCl}_{2}+$ OLA + TDPA, and (D) $\mathrm{CdCl}_{2}+$ OLA + ODPA.

$\mathrm{PbS}$ CQDs with different ligands were synthesized by a solvent thermal method reported previously [23]. Typically, $0.45 \mathrm{~g} \mathrm{PbO}, 1.5 \mathrm{~mL} \mathrm{OA}$, and $16.5 \mathrm{~mL}$ ODE were loaded into a three neck flask at $120{ }^{\circ} \mathrm{C}$ and degassed for $6 \mathrm{~h}$ to remove any moisture and low boiling point organic solvents. Then, $0.20 \mathrm{~mL}$ TMS mixed with $5 \mathrm{~mL}$ ODE was quickly injected into the reaction system. The hotplate was removed away immediately, and the reaction was cooled down to room temperature. When the temperature was dropped down to $90{ }^{\circ} \mathrm{C}$, different hybrid ligands $A, B, C$, or $D$ were injected into the reaction system, and the reaction was cool down to room temperature. Then, $50 \mathrm{~mL}$ acetone was injected into the final reaction solution to centrifuge at $10,000 \mathrm{rpm}$ for $5 \mathrm{~min}$. Black powder product was collected and re-dissolved into a mixture of $2 \mathrm{~mL}$ toluene and $10 \mathrm{~mL}$ of ethanol and acetone (volume ratio 1:1) to centrifuge again to remove impurity. This procedure was repeated more than three times to obtain pure PbS CQDs.

The above-mentioned hybrid ligands $B, C$, and $D$ were prepared by mixing $0.72 \mathrm{mmol} \mathrm{CdCl}_{2}, 2 \mathrm{~mL}$ OLA, and respective $0.048 \mathrm{mmol} \mathrm{OPA}, 0.048 \mathrm{mmol} \mathrm{TDPA}$, and $0.048 \mathrm{mmol}$ ODPA. The mixtures were degassed and refluxed at $90{ }^{\circ} \mathrm{C}$ for $5 \mathrm{~h}$ until transparent solutions were formed.

\subsection{Device Fabrication}

Figure 1 illustrates the fabrication processes of $\mathrm{PbS}$ CQDs solar cells with Schottky diode structure of ITO/PEDOT:PSS/PbS/Al. In detail, PEDOT:PSS layer was firstly deposited on ITO substrate and baked at $140{ }^{\circ} \mathrm{C}$ for $15 \mathrm{~h}$ after the substrate was treated with UV-ozone. The PbS CQDs film was deposited using a layer-by-layer spincoating process under ambient condition as the following steps: (i) $\mathrm{PbS}$ CQDs solution was deposited on above PEDOT:PSS layer by spin-coating at $2500 \mathrm{rpm}$ for $15 \mathrm{~s}$; (ii) MPA methanol solution was then spin casted to make ligands exchange; and (iii) Several drops of methanol solvent were deposited and spin casted at $2500 \mathrm{rpm}$ to remove impurities. The procedure from $\mathrm{i}$ to iii was repeated for several times until the film thickness reached about $200 \mathrm{~nm}$. Then, the film was baked at $50{ }^{\circ} \mathrm{C}$ for $10 \mathrm{~h}$. Finally, Al electrode in thickness of $\sim 80 \mathrm{~nm}$ was deposited on the active layer via thermal evaporation through a shadow mask, in which the active area was $0.16 \mathrm{~cm}^{2}$.

The fabrication process of solar cells with $\mathrm{p}-\mathrm{n}$ junction of $\mathrm{FTO} / \mathrm{ZnO} / \mathrm{TiO}_{2} / \mathrm{PbS} / \mathrm{Au}$ was almost similar except that FTO was used as the substrate, and $\mathrm{ZnO} / \mathrm{TiO}_{2}$ films were inserted between FTO and PbS by thermal decomposition of spin-casting $\mathrm{Zn} / \mathrm{Ti}$ precursor. The detailed process was described in the literatures [21, 28]. The Au electrode was deposited on the $\mathrm{PbS}$ active layer via thermal evaporation.

Space charge limited current (SCLC) measurement was carried out to investigate hole mobility of passivated $\mathrm{PbS}$ CQDs thin film. The measurement process was similar to that of PbS CQDs solar cells with Schottky diode structure except that $10 \mathrm{~nm} \mathrm{MoO}_{x}$ and $80 \mathrm{~nm}$ Al were deposited on the substrate via evaporation. In this case, the thickness of PbS CQDs thin film was about $200 \mathrm{~nm}$.

\subsection{Characterizations}

The morphology, structure, and surface state of PbS CQDs were characterized by transmission electron microscope (TEM, JEOL 2010), powder X-ray diffraction (XRD, Bruker D8), and X-ray photoelectron spectroscopy (XPS, Thermo ESCALAB 250), respectively. The optical properties of the samples were recorded by ultraviolet (UV) spectrophotometer (Shimadzu UV-3600). The currentvoltage $(\mathrm{J}-\mathrm{V})$ curves of solar cells were measured by a source-measurement unit under AM 1.5G spectrum (Keithley 2400) with a solar simulator (Oriel model 91192). The SCLC measurement was carried out on a semiconductor parameter analyzer (Agilent 4155C). 


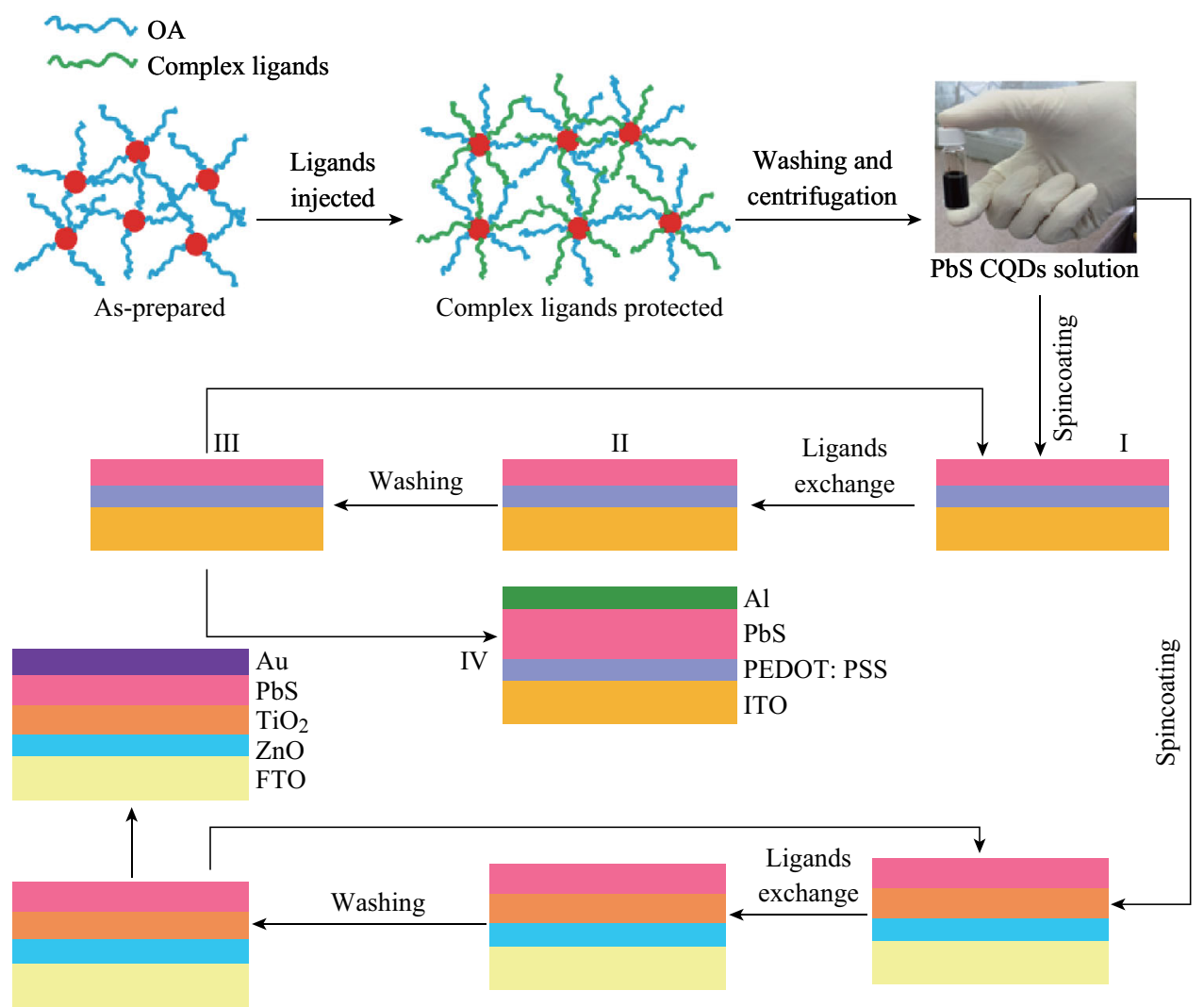

Fig. 1 The fabrication schematic of PbS CQDs solar cells passivated by hybrid ligands

\section{Results and Discussion}

The UV absorption spectra, TEM images, and XRD patterns of $\mathrm{PbS}$ CQDs with different passivating ligands are shown in Fig. 2. The UV absorption peak was at $1102 \mathrm{~nm}$ for CQDs without ligand protection $(A)$ as shown in Fig. 2a. The peaks blue shifted for those with hybrid ligands and the blue-shift amplitudes increase with increasing carboxyl chain of passivating ligands $(998 \mathrm{~nm}$ for ligand $B, 1040 \mathrm{~nm}$ for ligand $C$, and $1060 \mathrm{~nm}$ for ligand $D$ ). This may be due to the stronger absorption ability of the alkyl phosphate acid ligands with shorter carboxyl chains which could slow down the growth rate of $\mathrm{PbS}$ CQDs. From TEM images shown in Fig. 2b-e, one can see that the CQDs size particles are aggregate and the size without protection is larger of $4.6 \mathrm{~nm}$. The average size for ligand $\mathrm{B}, \mathrm{C}$, and $\mathrm{D}$ is, $3.5,3.5$ and $3.9 \mathrm{~nm}$, respectively. It was reported that the size decrease of PbS CQDs would result in the blue-shift of absorption peak [4], which is consistent with our results. Figure 2f shows XRD patterns of PbS CQDs with different ligands. The peaks are corresponding to (111), (200), (220), (311), (400), (331), (420), and (420) facets which are in well agreement with the standard cubic structure of PbS (JCPDS 02-0699).
The $\mathrm{J}-\mathrm{V}$ curves of CQDs solar cells are shown in Fig. 3a, and the device performances are listed in Table 1 . It can be noted that cells with hybrid ligands $(B, C$, and $D$ ) show much higher PCE values than those without ligand $(A)$. The cell with ligand $\mathrm{B}$ has higher values of $V_{\mathrm{oc}}=0.54 \mathrm{~V}, J_{\mathrm{sc}}=13.32 \mathrm{~mA} \mathrm{~cm}{ }^{-2}$, and $\mathrm{FF}=51.7 \%$, resulting in $\mathrm{PCE}=3.72 \%$. This value is higher than that of previous reported for $\mathrm{PbS} C \mathrm{CQDs}$ solar cells with the Schottky diode configuration [21, 29, 30]. However, the cell without ligand $(A)$ has less values of $V_{\mathrm{oc}}=0.36 \mathrm{~V}$, $J_{\mathrm{sc}}=5.541 \mathrm{~mA} \mathrm{~cm}^{-2}$, and $\mathrm{FF}=29.07 \%$, resulting in $\mathrm{PCE}=0.58 \%$. The former is six times higher than the latter. In addition, as the carbon chain length of alky phosphine increases, the values of $J_{\mathrm{sc}}, V_{\mathrm{oc}}$, and FF decrease accordingly, leading to the decrease of PCE (The PCE is $2.42 \%$ for ligand $C$ and $1.32 \%$ for ligand $D$ ). Figure $3 \mathrm{~b}$ shows the $\mathrm{J}-\mathrm{V}$ curves of PbS CQDs solar cells under dark. It is obvious that the dark current of the cell without ligand $(A)$ is much higher than those with hybrid ligands $(B, C$ and $D)$. This indicates that cells based on the hybrid ligands efficiently suppress the leakage current at the $\mathrm{PbS} / \mathrm{Al}$ interface. In the case of no hybrid ligand passivation, $\mathrm{PbS}$ CQDs are more likely attacked by oxygen in the reaction system or octane solvent, resulting in the generation of mid-gap trap states. To clarify this, XPS was carried out to 

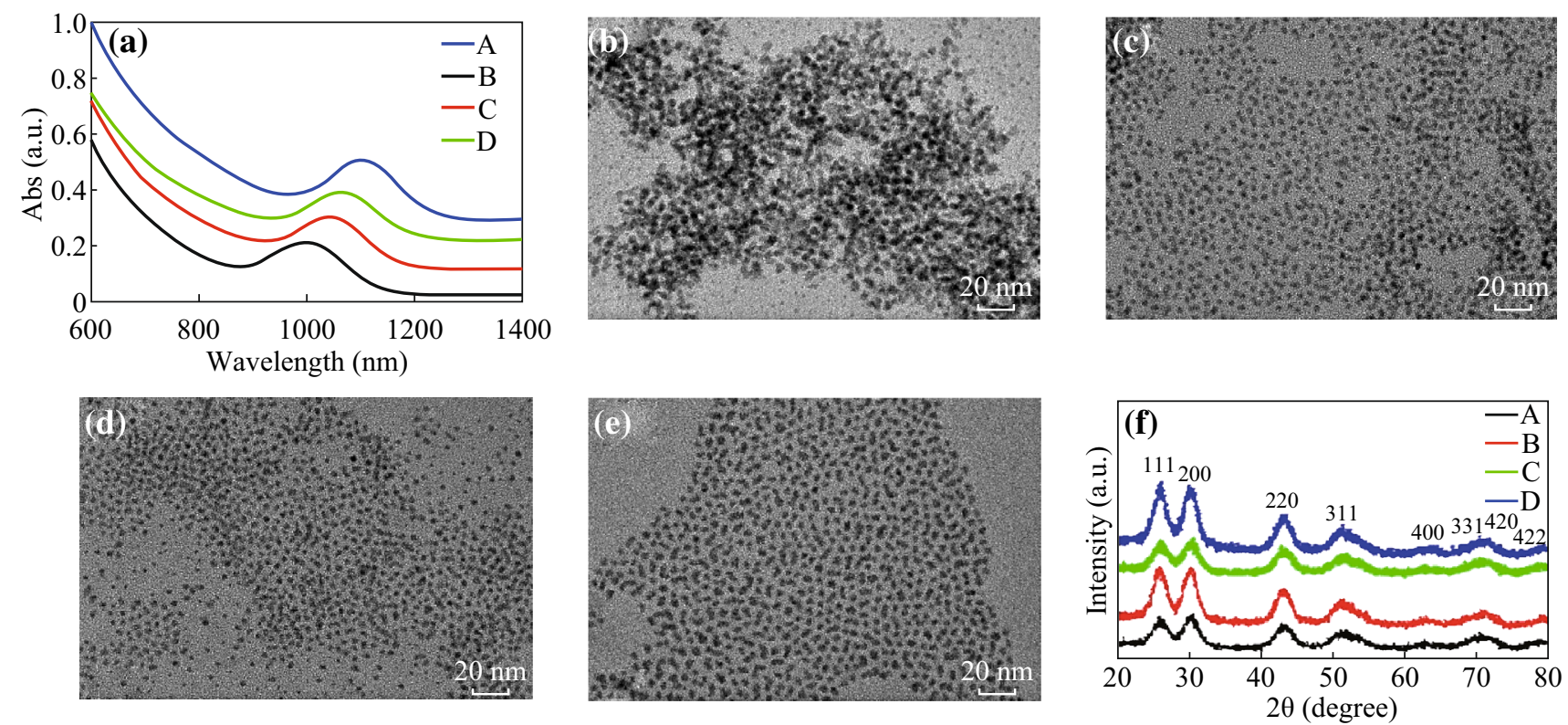

Fig. 2 a UV absorption spectra of PbS CQDs with different hybrid ligands. TEM images of PbS CQDs with different hybrid ligands: b without hybrid ligads (ligand $A$ ); $\mathbf{c} \mathrm{CdCl}_{2}+\mathrm{OLA}+\mathrm{OPA}$ (ligand $B$ ); $\mathbf{d ~} \mathrm{CdCl}_{2}+\mathrm{OLA}+\mathrm{TDPA}$ (ligand $C$ ); e CdCl $\mathrm{Cl}_{2}+\mathrm{OLA}+\mathrm{ODPA}$ (ligand $D$ ). f XRD patterns of $\mathrm{PbS}$ CQDs thin films with different complex ligands
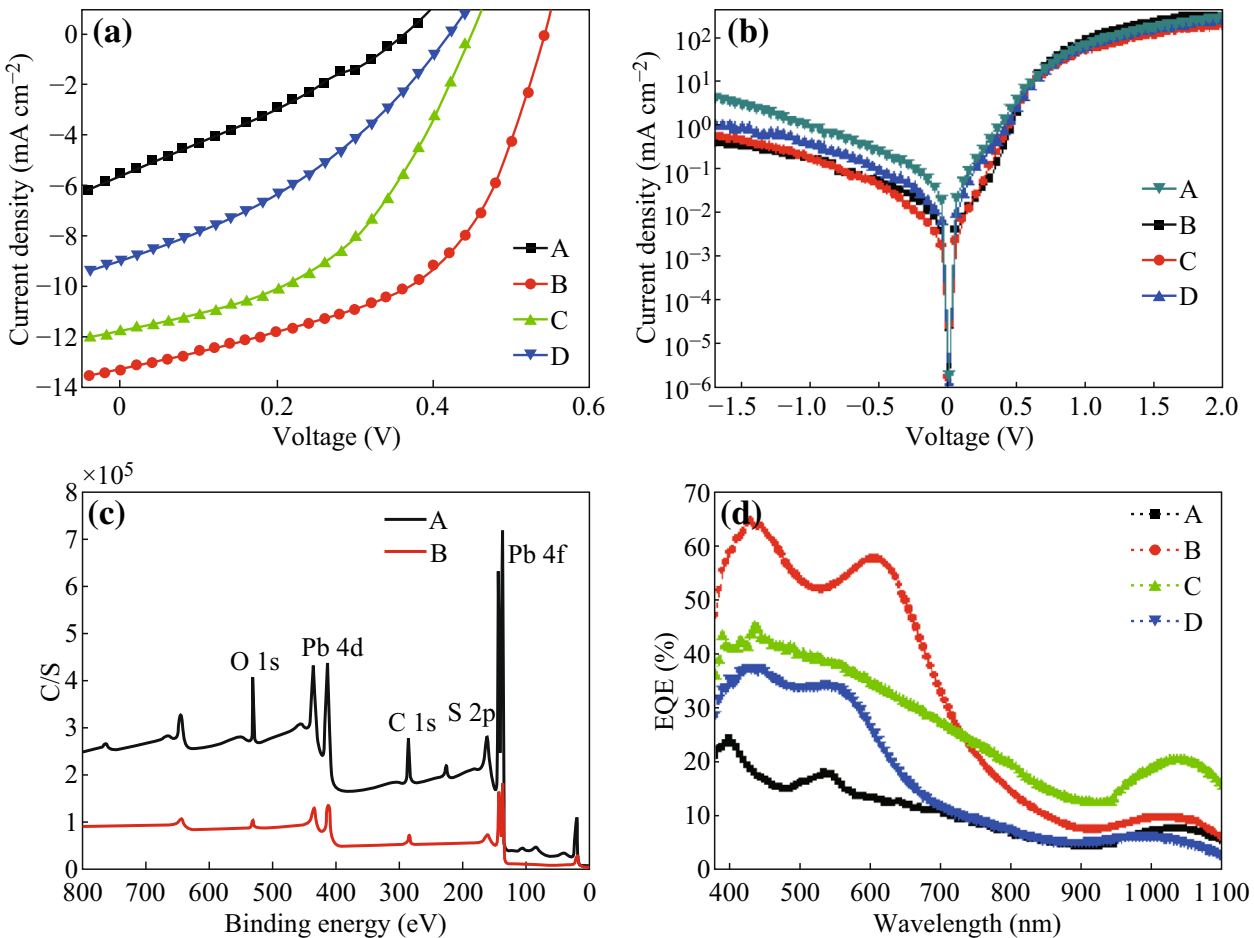

Fig. $3 \mathrm{~J}-\mathrm{V}$ curves of PbS CQDs solar cells with different hybrid ligands a under $100 \mathrm{~mW} \mathrm{~cm}{ }^{-2}$ AM1.5 illumination; b under dark. c XPS patterns of $\mathrm{PbS}$ thin films (ligands $A$ and $B$ ). d EQEs of PbS CQDs solar cells

characterize the surface state of different $\mathrm{PbS}$ thin films as shown in Fig. 3c. The atom percentage of different elements is summarized in Table 2 (Since ligand $C$ or $D$ has similar results to ligand $B$, their results did not present here). The presence of $\mathrm{Cl} 2 p$ metal chloride peak is related to the $\mathrm{CdCl}_{2}$ ligand which was injected during the formation of $\mathrm{PbS}$ CQDs in ligand $\mathrm{B}$-passivated $\mathrm{PbS}$. One can note that the peaks of metal oxide and thiol for PbS CQDs 
Table 1 Photovoltaic parameters of PbS CQDs Schottky diode cell with different hybrid ligands

\begin{tabular}{lllll}
\hline Devices & $V_{\text {oc }}(\mathrm{V})$ & $J_{\text {sc }}\left(\mathrm{mA} \mathrm{cm}^{-2}\right)$ & FF $(\%)$ & PCE $(\%)$ \\
\hline A & 0.36 & 5.541 & 29.07 & 0.58 \\
B & 0.54 & 13.320 & 51.70 & 3.72 \\
C & 0.44 & 11.830 & 46.49 & 2.42 \\
D & 0.42 & 8.932 & 35.18 & 1.32 \\
\hline
\end{tabular}

without ligand $(A)$ appear, whereas no such peaks observed in ligand $B$ sample. This indicates that hybrid ligands prevented the oxidation of PbS CQDs during device fabrication process, and MPA was removed thoroughly which was also observed by Sargent et al. [25]. The external quantum efficiency (EQE, see Fig. 3d) of PbS CQDs cells shows better response in the range of 400-800 $\mathrm{nm}$ for those with hybrid ligands.

Figure 4 shows the $\mathrm{J}-\mathrm{V}$ curves of $\mathrm{PbS}$ CQDs $\mathrm{p}-\mathrm{n}$ junction cells with different hybrid ligands (As devices based on PbS CQDs with ligand $D$ have similar results as that with ligand $C$, its $\mathrm{J}-\mathrm{V}$ curve is not presented here). Their performances are summarized in Table 3. For cell without ligand passivation (A), the PCE was only $1.71 \%$ coupled with low $J_{\mathrm{sc}}=11.11 \mathrm{~mA} \mathrm{~cm}^{-2}$ and $V_{\mathrm{oc}}=0.4 \mathrm{~V}$. On the contrary, the cell with ligand $B$ passivation shows
Table 3 Photovoltaic parameters of $\mathrm{PbS}$ CQDs $\mathrm{p}-\mathrm{n}$ junction cell with different hybrid ligands

\begin{tabular}{lllll}
\hline Devices & $V_{\mathrm{oc}}(\mathrm{V})$ & $J_{\mathrm{sc}}\left(\mathrm{mA} \mathrm{cm}^{-2}\right)$ & $\mathrm{FF}(\%)$ & PCE (\%) \\
\hline A & 0.40 & 11.11 & 38.5 & 1.71 \\
B & 0.46 & 23.3 & 47 & 5.04 \\
C & 0.48 & 13.81 & 43.1 & 2.86 \\
\hline
\end{tabular}

higher values of $V_{\mathrm{oc}}=0.46 \mathrm{~V}, J_{\mathrm{sc}}=23.30 \mathrm{~mA} \mathrm{~cm}^{-2}$, and $\mathrm{FF}=47 \%$, resulting in higher $\mathrm{PCE}=5.04 \%$, which is almost three times higher than that of cell without ligand passivation $(A)$ and $70 \%$ higher than that of cell with ligand $\mathrm{C}$ passivation. It was reported that $\mathrm{PbS} \mathrm{CQDs}$ solar cells with p-n junction of $\mathrm{PbS}-\mathrm{TiO}_{2}$ showed good stability over several months $[25,26]$. We also tested the stability of the as-prepared cells under ambient conditions in which the cell with ligand B was selected as an example. As shown in Fig. $4 \mathrm{~b}$, the device exhibits long-term storage stability in air, and the efficiency decreases less than $5 \%$ after 50 days storage.

Figure 5 shows the SCLC results of PbS CQDs films. The hole mobility was calculated by the formula of $J=$ $\frac{9}{8} \frac{\varepsilon \mu_{p} V^{2}}{L^{3}}$, [31], where $\varepsilon$ was the relative dielectric constant, and $L$ was the thickness of $\mathrm{PbS}$ active layer. A very low

Table 2 Atom percentage of element content of PbS CQDs solar cells with different hybrid ligands from XPS results

\begin{tabular}{|c|c|c|c|c|c|c|c|c|c|}
\hline \multirow[t]{2}{*}{ Sample } & \multicolumn{9}{|c|}{ Atom $(\%)$} \\
\hline & $\begin{array}{l}\mathrm{C} 1 \mathrm{~s} \\
\mathrm{C}-\mathrm{C}\end{array}$ & $\begin{array}{l}\mathrm{C} 1 \mathrm{~s} \\
\mathrm{C}=\mathrm{O}\end{array}$ & $\begin{array}{l}\mathrm{Cl} 2 \mathrm{p} \text { metal } \\
\text { chloride }\end{array}$ & $\begin{array}{l}\mathrm{Pb} 4 \mathrm{f} \\
(4 \mathrm{~d})\end{array}$ & $\begin{array}{l}\mathrm{S} 2 \mathrm{p} 3 \text { (S 2p1) } \\
\text { metal sulfide }\end{array}$ & $\begin{array}{l}\text { S 2p3 } \\
\text { (S 2p1) thiol }\end{array}$ & $\begin{array}{l}\mathrm{O} 1 \mathrm{~s} \\
\text { carbonates/sulfates }\end{array}$ & $\begin{array}{l}\text { O 1s metal } \\
\text { oxide }\end{array}$ & $\begin{array}{l}\mathrm{S} 2 \mathrm{p} 3 \\
\text { (S 2p1) sulfate }\end{array}$ \\
\hline A-passivated $\mathrm{PbS}$ & 33.65 & 5.95 & 0 & 10.65 & 19.01 & 6.9 & 20.83 & 0.57 & 2.44 \\
\hline B-passivated $\mathrm{PbS}$ & 36.7 & 4.94 & 2.88 & 11.39 & 26.81 & 3.76 & 13.53 & 0 & 0 \\
\hline
\end{tabular}
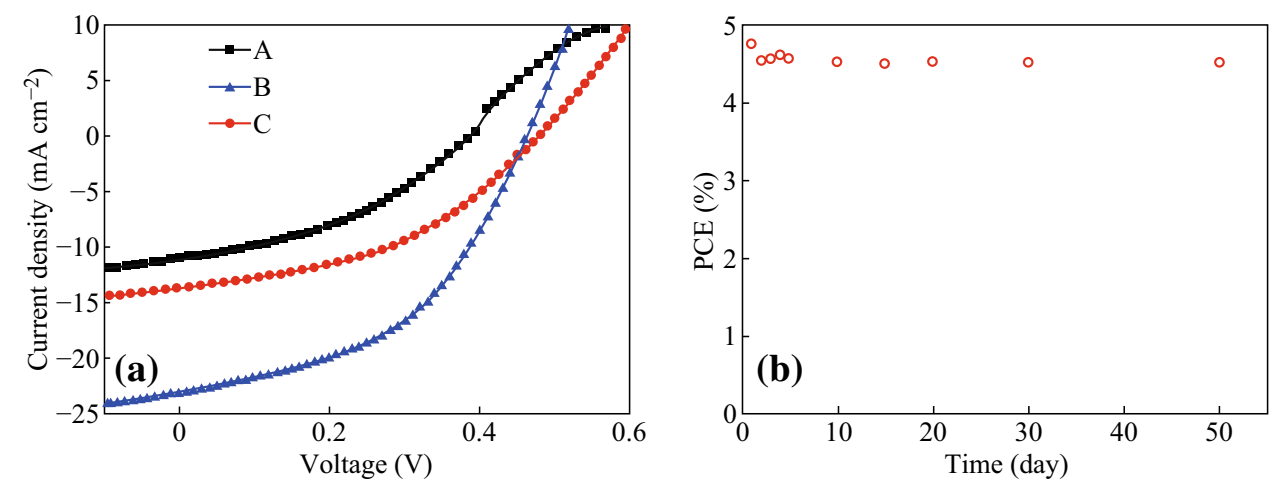

Fig. 4 a J-V curves of p-n junction PbS CQDs cells with different hybrid ligands $(A, B$ and $C)$. b Stability of PbS/TiO ${ }_{2}$ CQDs solar cells devices fabricated using $\mathrm{PbS}$ CQDs passivated by ligand $\mathrm{B}$ 

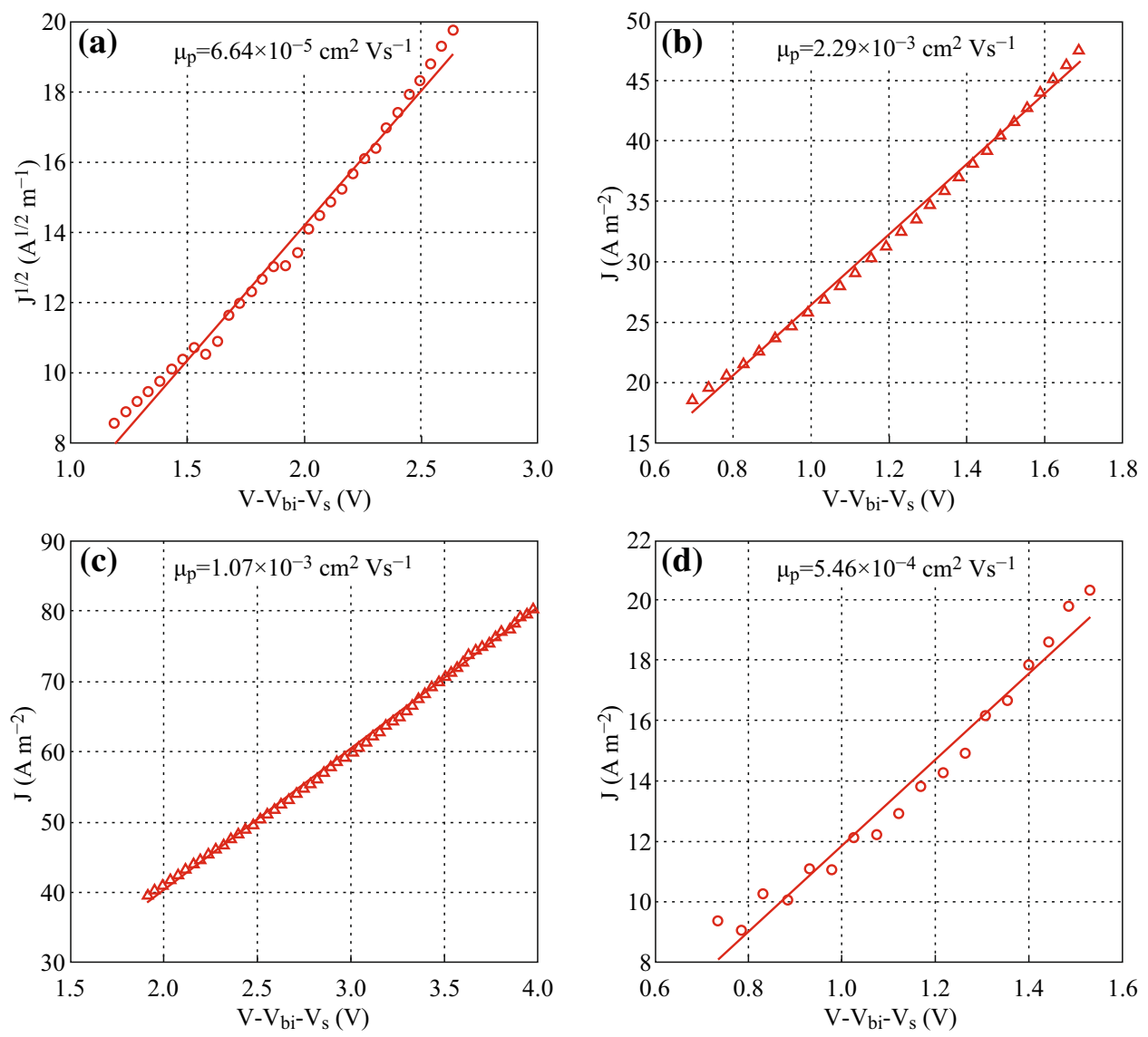

Fig. 5 SCLC measurements of PbS CQDs thin films with different hybrid ligands a ligand $A$, b ligand $B$, $\mathbf{c}$ ligand $C$, and $\mathbf{d}$ ligand $D$

hole mobility of $6.64 \times 10^{-5} \mathrm{~cm}^{2} \mathrm{Vs}^{-1}$ was observed in $\mathrm{PbS}$ thin film without ligand passivation $(A)$, which indicates that large surface states exist in the film. While the hole mobility increases for those with hybrid ligands passivation, and the values are, respectively, $1.07 \times 10^{-3}$ and $5.46 \times 10^{-4} \mathrm{~cm}^{2} \mathrm{Vs}^{-1}$ for ligand $C$ and $D$. It reaches the highest of $2.29 \times 10^{-3} \mathrm{~cm}^{2} \mathrm{Vs}^{-1}$ for ligand $B$. The increased hole mobility can improve the cell performance due to recombination reduction of electron and hole during carrier transfer, and therefore, higher $J_{\mathrm{sc}}$ can be expected. This is consistent with the $\mathrm{J}-\mathrm{V}$ results (see Table 1). It could be concluded that although $\mathrm{CdCl}_{2}$ played a determinative role in mid-gap state passivation [25], the choice of alkyl phosphine acid is more important to improve transport ability associated with the valence band.

\section{Conclusion}

In summary, novel hybrid ligands were developed to passivate $\mathrm{PbS}$ CQDs, and the performance of as-prepared $\mathrm{PbS}$ CQDs solar cells with not only Schottky diode structure but also $\mathrm{p}-\mathrm{n}$ junction structure was improved. The reason is that the hybrid ligands passivate surface defects well and prevent oxidation of PbS CQDs during the device fabrication process. In addition, the shorter the chain length of phosphine in hybrid ligands, the higher hole mobility and PCE were demonstrated in cells. Especially, the PbS CQDs cell with ligand B in Schottky diode structure has the highest PCE value compared with reported cells with other ligands. Our results provide an effective way to improve the performance of PbS CQDs solar cells.

Acknowledgments We thank the financial support of the National Natural Science Foundation of China (No. 91333206, 61274062, and 11204106), National Science Foundation for Distinguished Young Scholars of China (Grant No. 51225301), and Guangdong Province Natural Science Fund (No. 2014A030313257).

Open Access This article is distributed under the terms of the Creative Commons Attribution 4.0 International License (http://creativecommons.org/licenses/by/4.0/), which permits unrestricted use, distribution, and reproduction in any medium, provided you give appropriate credit to the original author(s) and the source, provide a link to the Creative Commons license, and indicate if changes were made.

\section{References}

1. I.J. Kramer, L. Levina, R. Debnath, D. Zhitomirsky, E.H. Sargent, Solar cells using quantum funnels. Nano Lett. 11(9), 3701-3706 (2011). doi:10.1021/n1201682h 
2. O.E. Semonin, J.M. Luther, S. Choi, H.Y. Chen, J. Gao, A.J. Nozik, M.C. Beard, Peak external photocurrent quantum efficiency exceeding $100 \%$ via meg in a quantum dot solar cell. Science 334(6062), 1530 (2011). doi:10.1126/science.1209845

3. I. Gur, N.A. Fromer, M.L. Geier, A.P. Alivisatos, Air-stable allinorganic nanocrystal solar cells processed from solution. Science 310(5747), 462 (2005). doi:10.1126/science.1117908

4. J. Tang, E.H. Sargent, Infrared colloidal quantum dots for photovoltaics: fundamentals and recent progress. Adv. Mater. 23(1), 12-29 (2011). doi:10.1002/adma.201001491

5. M.G. Panthani, J.M. Kurley, R.W. Crisp, T.C. Dietz, T. Ezzyat, J.M. Luther, D.V. Talapin, High efficiency solution processed sintered CdTe nanocrystal solar cells: the role of interfaces. Nano Lett. 14(2), 670-675 (2014). doi:10.1021/nl403912w

6. J. Zhu, Y. Yang, Y. Gao, D. Qin, H. Wu, L. Hou, W. Huang, Enhancement of open-circuit voltage and the fill factor in CdTe nanocrystal solar cells by using interface materials. Nanotechnology 25(36), 365203 (2014). doi:10.1088/0957-4484/25/36/ 365203

7. Y. Tian, Y. Zhang, Y. Lin, K. Gao, Y. Zhang et al., Solutionprocessed efficient CdTe nanocrystal/CBD-CdS heterojunction solar cells with $\mathrm{ZnO}$ interlayer. J. Nanoparticle Res. 15, 2053 (2013). doi:10.1007/s11051-013-2053-Z

8. Z. Chen, H. Zhang, X. Du, X. Cheng, X. Chen, Y. Jiang, B. Yang, From planar-heterojunction to n-i structure: an efficient strategy to improve short-circuit current and power conversion efficiency of aqueous-solution-processed hybrid solar cells. Energy Environ. Sci. 6, 1597-1603 (2013). doi:10.1039/c3ee40481a

9. Z. Chen, H. Zhang, Q. Zeng, Y. Wang, D. Xu, L. Wang, H. Wang, B. Yang, In situ construction of nanoscale CdTe-CdS bulk heterojunctions for inorganic nanocrystal solar cells. Adv. Energy Mater. 4(10), 1400235 (2014). doi:10.1002/aenm.201400235

10. Y.-G. Nir, S.-H. Michal, Z. Marina, K. Shifi, S. Asher, T. Nir, Molecular control of quantum-dot internal electric field and its application to CdSe-based solar cells. Nat. Mater. 10, 974-979 (2011). doi:10.1038/nmat3133

11. E.J.D. Klem, C.W. Gregory, G.B. Cunningham, S. Hall, D.S. Temple, J.S. Lewis, Planar PbS quantum dot/C60 heterojunction photovoltaic devices with $5.2 \%$ power conversion efficiency. Appl. Phys. Lett. 100(17), 173109 (2012). doi:10.1063/1.4707377

12. D.C.J. Neo, C. Cheng, S.D. Stranks, S.M. Fairclough, J.S. Kim et al., Influence of shell thickness and surface passivation on $\mathrm{PbS} /$ CdS core/shell colloidal quantum dot solar cells. Chem. Mater. 26(13), 4004-4013 (2014). doi:10.1021/cm501595u

13. G.H. Kim, B. Walker, H.B. Kim, J.Y. Kim, E.H. Sargent, J. Park, J.Y. Kim, Inverted colloidal quantum dot solar cells. Adv. Mater. 26(20), 3321-3327 (2014). doi:10.1002/adma.201305583

14. B.A. Gonfa, H. Zhao, J. Li, J. Qiu, M. Saidani et al., Air-processed depleted bulk heterojunction solar cells based on $\mathrm{PbS} / \mathrm{CdS}$ core-shell quantum dots and $\mathrm{TiO}_{2}$ nanorod arrays. Sol. Energy Mater. Sol. Cells 124, 67-74 (2014). doi:10.1016/j.solmat.2014. 01.037

15. W. Ma, S.L. Swisher, T. Ewers, J. Engel, V.E. Ferry, H.A. Atwater, A.P. Alivisatos, Photovoltaic performance of ultrasmall PbSe quantum dots. ACS Nano 5(10), 8140-8147 (2011). doi:10. $1021 / \mathrm{nn} 202786 \mathrm{~g}$

16. M. Tabachnyk, B. Ehrler, S. Gelinas, M.L. Bohm, B.J. Walker et al., Resonant energy transfer of triplet excitons from pentacene to PbSe nanocrystals. Nat. Mater. 13, 1033-1038 (2014). doi:10. $1038 /$ nmat4093
17. J. Gao, J.M. Luther, O.E. Semonin, R.J. Ellingson, A.J. Nozik, M.C. Beard, Quantum dot size dependent J-V characteristics in heterojunction $\mathrm{ZnO} / \mathrm{PbS}$ quantum dot solar cells. Nano Lett. 11(3), 1002-1008 (2011). doi:10.1021/nl103814g

18. B.D. Weil, S.T. Connor, Y. Cui, $\mathrm{CuInS}_{2}$ solar cells by air-stable ink rolling. JACS 132(13), 6642-6643 (2010). doi:10.1021/ ja1020475

19. M.A. Hines, G.D. Scholes, Colloidal PbS nanocrystals with sizetunable near-infrared emission: observation of post-synthesis self-narrowing of the particle size distribution. Adv. Mater. 15(21), 1844-1849 (2003). doi:10.1002/adma.200305395

20. S.A. McDonald, G. Konstantatos, S. Zhang, P.W. Cyr, E.J.D. Klem, L. Levina, E.H. Sargent, Solution-processed PbS quantum dot infrared photodetectors and photovoltaics. Nat. Mater. 4, 138-142 (2005). doi:10.1038/nmat1299

21. J. Tang, X. Wang, L. Brzozowski, D.A.R. Barkhouse, R. Debnath, L. Levina, E.H. Sargent, Schottky quantum dot solar cells stable in air under solar illumination. Adv. Mater. 22(12), 1398-1402 (2010). doi:10.1002/adma.200903240

22. J.M. Luther, M. Law, M.C. Beard, Q. Song, M.O. Reese, R.J. Ellingson, A.J. Nozik, Schottky solar cells based on colloidal nanocrystal films. Nano Lett. 8(10), 3488-3492 (2008). doi:10. $1021 / \mathrm{n} 1802476 \mathrm{~m}$

23. D. Zhitomirsky, M. Furukawa, J. Tang, P. Stadler, S. Hoogland, O. Voznyy, H. Liu, E.H. Sargent, N-type colloidal-quantum-dot solids for photovoltaics. Adv. Mater. 24(46), 6181-6185 (2012). doi:10.1002/adma.201202825

24. H. Liu, J. Tang, I.J. Kramer, R. Debnath, G.I. Koleilat et al., Electron acceptor materials engineering in colloidal quantum dot solar cells. Adv. Mater. 23(33), 3832-3837 (2011). doi:10.1002/ adma.201101783

25. A.H. Ip, S.M. Thon, S. Hoogland, O. Voznyy, D. Zhitomirsky, R. Debnath, L. Levina, A. Amassian, E.H. Sargent, Hybrid passivated colloidal quantum dot solids. Nat. Nanotechnol. 7(9), 577-582 (2012). doi:10.1038/nnano.2012.127

26. C.M. Chuang, P.R. Brown, V. Bulovic, M.G. Bawendi, Improved performance and stability in quantum dot solar cells through band alignment engineering. Nat. Mater. 13, 796-801 (2014). doi:10. 1038/nmat3984

27. Z. Ning, O. Voznyy, J. Pan, S. Hoogland, V. Adinolfi et al., Airstable n-type colloidal quantum dot solids. Nat. Mater. 13, 822-828 (2014). doi:10.1038/nmat4007

28. L.J. Kramer, E.H. Sargent, The architecture of colloidal quantum dot solar cells: materials to devices. Chem. Rev. 114(1), 863-882 (2014). doi:10.1021/cr400299t

29. W. Yoon, J.E. Boercker, M.P. Lumb, D. Placencia, E.E. Foos, J.G. Tischler, Enhanced open-circuit voltage of $\mathrm{PbS}$ nanocrystal quantum dot solar cells. Sci. Rep.-UK 3, 2225 (2013). doi:10. 1038/srep02225

30. V. Malgras, A. Nattestad, Y. Yamauchi, S.X. Dou, J.H. Kim, The effect of surface passivation on the structure of sulphur-rich $\mathrm{PbS}$ colloidal quantum dots for photovoltaic application. Nanoscale 7(13), 5706-5711 (2015). doi:10.1039/C4NR07006B

31. R. Ciach, Y.P. Dotsenko, V.V. Naumov, A.N. Shmyryeva, Injection technique for the study of solar cell test structures. Sol. Energy Mater. Sol. Cells 76(4), 613-624 (2003). doi:10.1016/ S0927-0248(02)00271-4 